\section{Influence of a Retentive Shoulder Design to Prevent Early Failure of Three Core Build-Ups}

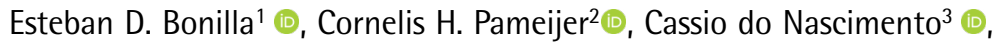

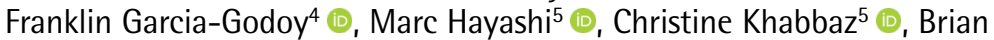
C. Bonilla ${ }^{6} \mathbb{D}$, Vinicius Pedrazzi ${ }^{3}$ (D)

This study evaluated the influence of a retentive shoulder design to prevent early failure of three resin composite build-ups on molars. Ninety-six intact extracted human maxillary third molars were assigned to two groups $(n=48)$ based on occlusal, buccal cusps only and all cusps reduction. The groups were divided into two subgroups: pin retained and nonpin retained build-ups resulting in four groups $(n=24)$, according the cusps reduction: pin retained/partial, pin retained/complete, non-pin retained/partial, non-pin retained/complete. Occlusal reduction was $3 \mathrm{~mm}$ with a semi-lunar retentive shoulder of $3 \mathrm{~mm}$ and an axial wall height of $1.5 \mathrm{~mm}$. Groups were restored using a microhybrid, flowable or titanium reinforced resin composite. Modified self-curing acrylic resin provisional crowns were fabricated, cemented with non-eugenol temporary cement and thermal cycled. An instron machine applied tension to the provisional crowns parallel to the long axis of the tooth until dislodgement. A three-way analysis of variance was conducted on the influence of the variables on the retention of the core build-up. Ninety-three build-ups were retained under tensile load, while three core build-ups without pins were dislodged. Three-way analysis of variance showed no statistically significant difference between core build-ups using a retentive shoulder and pin retained core build-ups when tested under tensile load. With the advent of adhesive systems, increased surface area and retentive shoulder design can provide a retentive core foundation to prevent early failures of core build-ups during indirect restoration fabrication which will contribute to the longevity of final restorations.
'University of California School of Dentistry, Lecturer of Section of Restorative Dentistry, Los Angeles, CA, USA

${ }^{2}$ University of Connecticut School of Dental Medicine, Professor Emeritus, CT, USA ${ }^{3}$ School of Dentistry of Ribeirão Preto, Professor of Department of Dental Materials and Prosthodontics, Molecular Diagnosis Laboratory, USP - Universidade de São Paulo, Ribeirão Preto, SP, Brazil ${ }^{4}$ University of Tennessee Health Science Center, Director and Professor of Department of Bioscience Research Center, Memphis, TN, USA ${ }^{5}$ University of California School of Dentistry, Section of Restorative Dentistry, Los Angeles, CA, USA ${ }^{6}$ Santa Clara University, Leavey School of Business, Santa Clara, CA, USA

Correspondence: Prof. Dr. Vinicius Pedrazzi, Avenida do Café s, 14040-904 Ribeirão Preto, SP, Brasil. Tel: +55-16-3315-4008. e-mail: pedrazzi@forp.usp.br

Key Words: resin composite, core materials, retention, retentive shoulder design, pin retention.

\section{Introduction}

A variety of restorative materials and techniques have been used to fabricate core build-ups on vital posterior teeth that are to be restored with an indirect restoration (1-3). Most of these materials were not specifically developed for the purpose of build-ups, but due to their physical properties have found applications in this procedure $(4,5)$. To facilitate retention of these materials in severely compromised teeth due to caries, fractured cusps or the presence of large restorations; pins have been utilized $(5,6)$. Placement of pins, however, is technique sensitive and is not without certain risks. Pin insertion may cause internal stress, pulpal exposure or root perforation, causing bacterial ingress or irreversible pulpal inflammation, which will lead to endodontic treatment (4,5,7-11).

The use of pin retention for retaining cores has decreased considerably since the advent of bonding agents (6). However, the issue of lack of retention of core buildups still remains problematic, especially during the final impression stage or when removing a provisional restoration. The authors have defined this as early failure of the core build-up. As a result, compromised vital posterior teeth that have lost one half of the clinical crown still often require additional retentive features, such as pins for build-ups, prior to cementing the final restoration $(12,13)$.

Given the inherent risks of pin placement and retention issues with composite resin build-ups, an alternative method to build-ups would be desirable. The use of grooves, slots, boxes and adhesive bonding has been investigated with success in extensive restorations $(14,15)$, and appear to be less of a risk to the pulp than pins (7). However, there is a lack of evidence supporting specific techniques to prevent early failures of resin build-ups on compromised vital posterior teeth $(15,16)$. Since incorporating vertical and horizontal components to the tooth structure is recommended to improve core retention (12) we propose a novel intra-coronal preparation design, the "retentive shoulder".

The retentive shoulder design is intended for use on vital molars exhibiting extensive loss of sound tooth structure, such as two or three major cusps, which require a build-up prior to crown fabrication. The basic premise of this design is the increase in surface area that enhances retention of composite resin to natural tooth structure. The design not only enhances retention form, but also increases resistance 
against dislodgment forces the build-up may experience on compromised vital posterior teeth during fabrication of the indirect definitive restoration. Thus, the aim of this in vitro study was to evaluate the influence of a retentive shoulder design to prevent early failure of three resin composite build-ups under tensile forces. In the control groups, pin retained resin composite build-ups were tested. The null hypothesis stated that there is no difference in the retention of three core build-ups restored by means of the retentive shoulder design compared to pin-retained build-up. If the null hypothesis is proven the need for the use of pins for retention can mostly be avoided, thus reducing inherent risks of root perforation or pulp exposure.

\section{Material and Methods}

This study was approved and conducted in full accordance with the Ethics Committee of the Section of Restorative Dentistry at UCLA School of Dentistry CA, USA.

\section{Study Design and Preparation of Teeth}

Ninety-six intact $(n=96)$ caries free, freshly extracted human maxillary third molars of comparable size (mesiobuccal $=9.5$ to $10 \mathrm{~mm}$ and bucco-lingual $=9.5$ to 10

structural defects when examined under a stereomicroscope (Nikon SMZ645, Tokyo, Japan) at x40 magnification. The roots of suitable molars were notched ( $0.5 \mathrm{~mm}$ in depth) using a
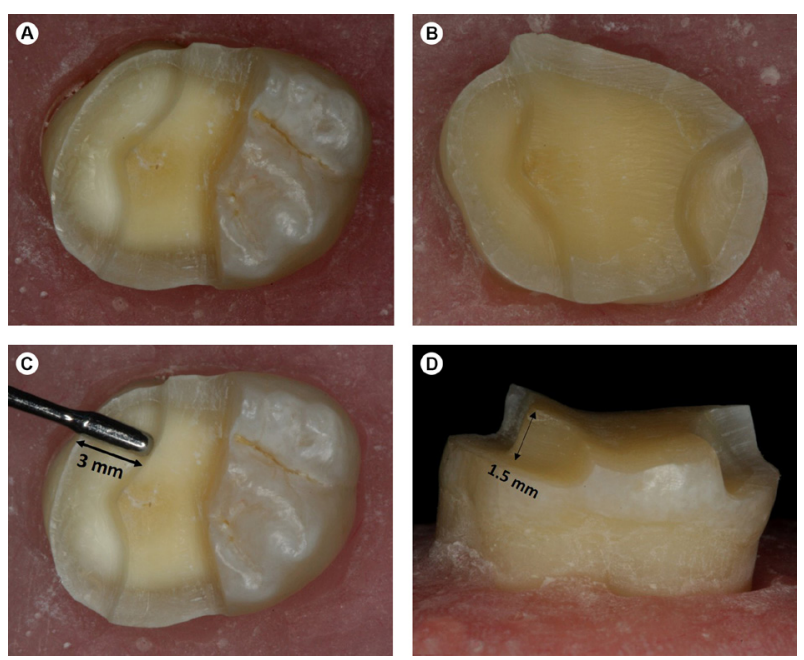

Figure 1. Milled crowns showing both partial and complete cusp removal. Tooth preparation involved (A) two retentive shoulders (buccal cusps) or (B) three retentive shoulders (two buccal and one palatal cusp); (C) Black arrow indicates depth of the shoulder (3 $\mathrm{mm}$ ); (D) Proximal view of three shoulder preparations with complete cusp removal. Black arrow indicates axial height $(1.5 \mathrm{~mm})$
169L carbide tapered fissure bur (Brasseler, Savannah GA, USA) to create retention. The teeth were then imbedded in auto polymerizing acrylic resin (Co-Oral-Ite; Dental Mfg, Diamond Springs, CA, USA), leaving $3.0 \mathrm{~mm}$ of root exposed when measured from the CEJ.

Teeth were assigned to two groups $(n=48)$ based on the extent of occlusal reduction: Group I: missing both buccal cusps and Group II: all cusps missing. Each group was subsequently further subdivided into two groups $(n=24)$ : A: Pin retained and B: Non-pin retained build-ups. Extra coarse flat ended diamond burs (5845KR-025; Brasseler, Savannah GA, USA) measuring $2.5 \mathrm{~mm}$ in diameter and $4 \mathrm{~mm}$ in height were used for $3 \mathrm{~mm}$ occlusal reduction of the mesio-buccal and disto-buccal cusps parallel to the inclined cusp planes in Group I. In Group II, both buccal and lingual cusps underwent $3 \mathrm{~mm}$ of occlusal reduction in similar fashion.

\section{Retentive Shoulder Design}

The retentive shoulder design was semi-lunar in shape with a horizontal depth of $3 \mathrm{~mm}$ and a slightly tapered axial wall measuring $1.5 \mathrm{~mm}$ in height (Fig. 1). In both groups under copious water cooling a retentive shoulder was prepared for each removed cusp.

To standardize the preparation of the retentive shoulder, a handpiece (Tradition Midwest, Dentsply,York PA, USA) was mounted in a surveyor (Ney Products International Inc, Bloomfield CT, USA). Half $(n=24)$ of the retentive shoulder design teeth received a pin (Max 021; Coltene/ Whaledent, Inc., Cuyahoga Falls OH, USA), which was a self-threading para-pulpal retention pin with a shoulder stop and rounded head designed to provide retention for the build-up materials. Pins were inserted according to the
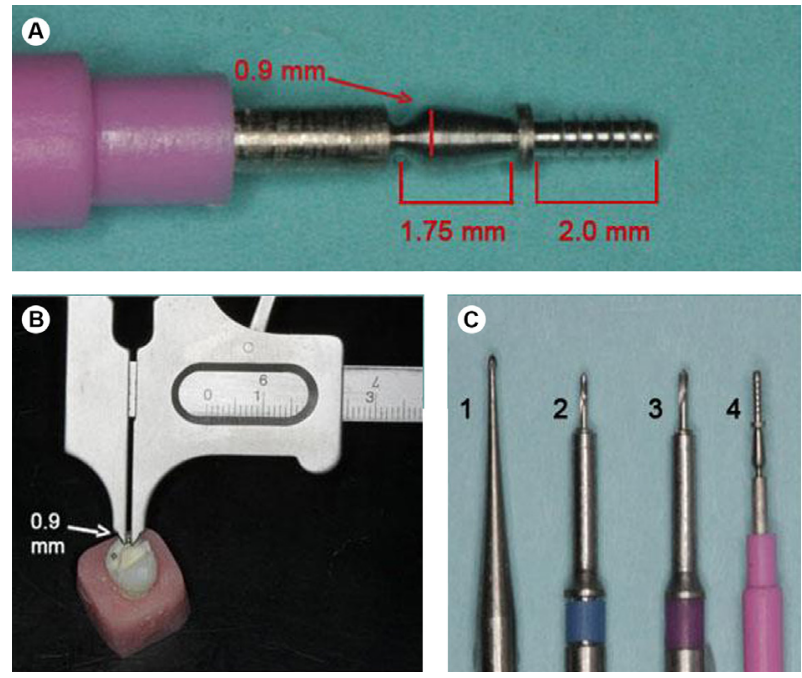

Figure 2. (A) Dimension of Max 21 pin (B) Diameter of the head of Max 21 pin (C) Sequence of pin placement drills 
manufacturer's instructions. After a pilot indentation of 0.5 $\mathrm{mm}$ with a $1 / 4$ round FG carbide bur (Brasseler, Savannah GA, USA) located at least $1 \mathrm{~mm}$ from the DE-junction, a pin hole was prepared with 0.017 " and $0.021 "$ twist drills in a low speed contra angle handpiece (Max 021; Coltene/ Whaledent, Inc., Cuyahoga Falls $\mathrm{OH}$, USA) to a depth of $2 \mathrm{~mm}$ (Fig. 2). Then the pin Max 21 was inserted using a low speed contra angle until it sheared from the shaft resulting in a $1.75 \mathrm{~mm}$ extruded pin, plus the width of the stop (Fig. 3) (17).

The groups were then further divided into type of build-up materials that were used: Herculite XRV, Light cure (Kerr dental products, Orange CA, USA) $(n=8)$, CoreFlo DC, Dual cure (BISCO dental products, Schaumburg IL, USA) $(n=8)$, and Ti-Core Auto E, Dual cure (Essential Dental Systems, South Hackensack NJ, USA) $(n=8)$. All restorations were placed following the manufacturer's instructions and with the recommended etchant and bonding agents (Table 1). Herculite XRV resin composite was placed in 2

Table 1. Core build-up materials and recommended etch and bonding agents

\begin{tabular}{lcc}
\hline Composite & Etchant & $\begin{array}{c}\text { Bonding } \\
\text { Agent }\end{array}$ \\
\hline $\begin{array}{l}\text { Ti-Core Auto E, Dual } \\
\text { cure (Essential Dental } \\
\text { Systems, NJ, USA) }\end{array}$ & $\begin{array}{c}\text { Gel Etchant 37.5\% } \\
\text { phosphoric acid }\end{array}$ & OptiBond FL \\
& Uni-Etch 32\% & ACE ALL- \\
$\begin{array}{l}\text { Core-Flo DC, Dual } \\
\text { cure (Bisco, IL, USA) }\end{array}$ & $\begin{array}{c}\text { Benzalkonium } \\
\text { Chloride }\end{array}$ \\
$\begin{array}{l}\text { Herculite XRV, Light } \\
\text { cure (Kerr, CL, USA) }\end{array}$ & $\begin{array}{c}\text { Gel Etchant 37.5\% } \\
\text { phosphoric acid }\end{array}$ & OptiBond FL \\
\hline
\end{tabular}
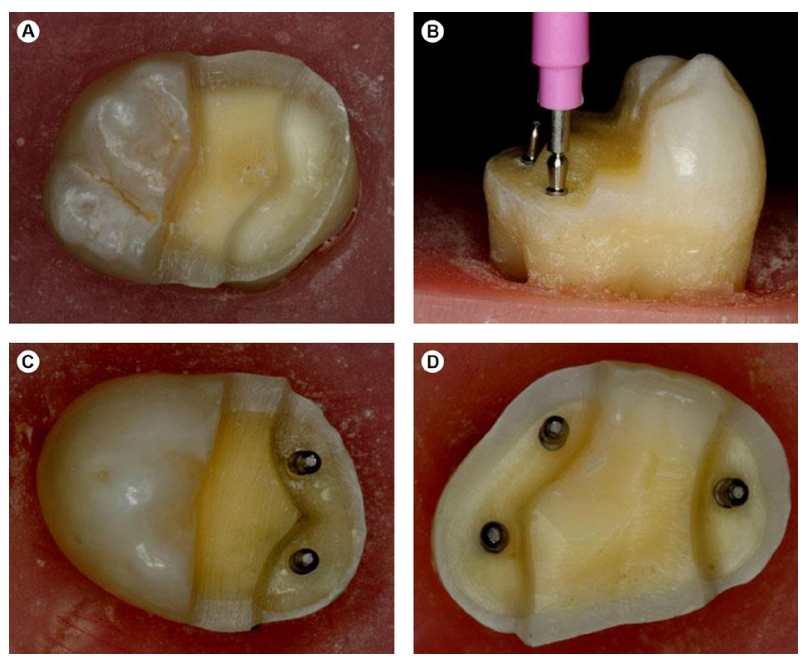

Figure 3. (A) Occlusal view of retentive shoulder design of buccal cusps missing (B) Placement of Max 21 pin, 2 mm in depth (C) Representation of pin placement, one pin for missing cusp (D) Representation of placement of three pins $\mathrm{mm}$ increments, each light cured for $20 \mathrm{~s}$ using an Elipar Deep Cure-S LED curing light operating at $1000 \mathrm{~mW} / \mathrm{cm} 2$ (3M ESPE, St. Paul MN, USA).

\section{Complete Crown Tooth Preparation}

Once build-up materials were placed, standardized preparations for all-ceramic crowns were made using an extra-coarse round-end diamond bur to prepare the axial walls (5856-016; Brasseler, Savannah GA, USA) with a highspeed handpiece (Tradition Midwest, Dentsply, York PA, USA) attached to a dental surveyor (Ney products International Inc, Bloomfield CT, USA) under constant water cooling. The preparation was refined with a fine-grit modified flat-ended diamond bur (8845-016; Brasseler, Savannah GA, USA) under the same water irrigation conditions. The preparations had $2 \mathrm{~mm}$ occlusal reduction, a circumferential shoulder margin of $1 \mathrm{~mm}$, rounded internal line angles and axial walls with an angle of convergence of 12 degrees. The last was verified with a Goniometer quick-angle protractor ruler (Westcott, Fairfield CT, USA). The height of the bucco-lingual axial walls was $5.5 \mathrm{~mm}$ with interproximal axial walls of $4 \mathrm{~mm}$ as measured by a digital caliper (AicKar, Shenzhen GD, China) (Fig. 4). After completion of the preparations provisional crowns were
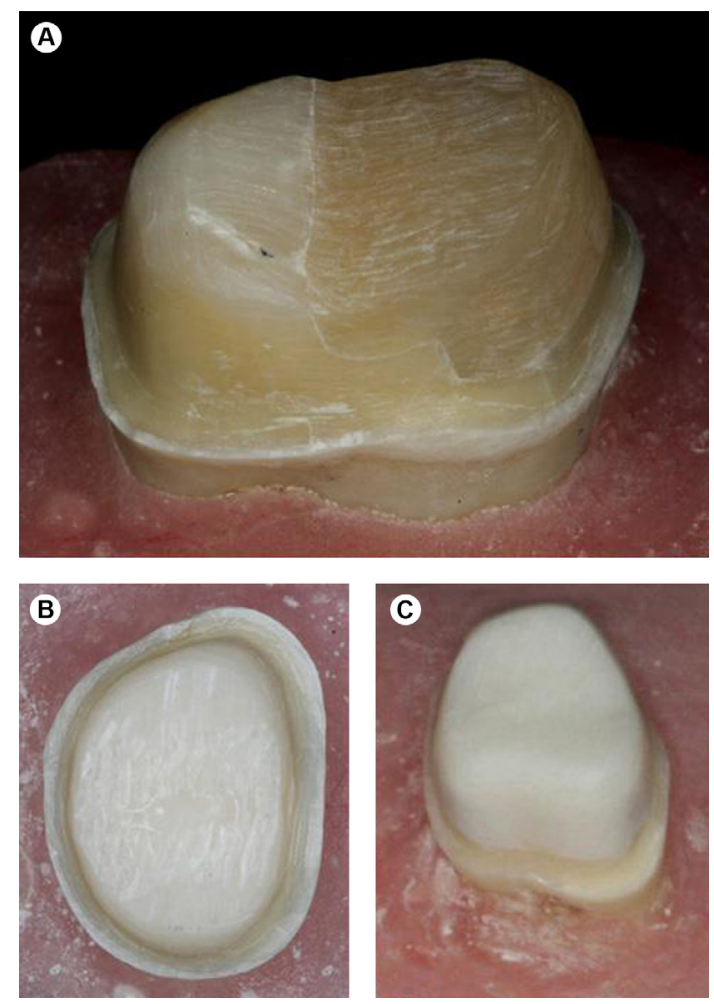

Figure 4. (A) Occlusal view of completed preparation with Herculite XRV covering two cusps without pins; (B) Occlusal view of complete preparation with Ti-Core Auto covering all cusps and no pins; (C) Core Flo build-up covering all cusps without the use of pins 
fabricated using auto-polymerizing resin (Jet acrylic Lang Dental, Wheeling IL, USA). One and the same operator used a direct technique resulting in provisionals with dimensions of $21 \mathrm{~mm}$ in height and $13 \mathrm{~mm}$ in width. A modified occlusal surface allowed for an orthodontic wire to securely loop through a $1 \mathrm{~mm}$ hole, enabling attachment to a Universal testing machine (Fig. 5A) (Model 5966, Instron; Instron Corp, Norwood MA). The provisional crowns were stored in distilled water at room temperature for $24 \mathrm{~h}$ before cementation.

\section{Cementation of Provisional Crown and Testing}

Non-eugenol provisional cement (Temp Bond NE; Kerr dental products, Orange CA, USA) was mixed according to the manufacturer's recommendations. A thin layer of cement was applied to the internal fitting surface of the crown, which after placement was held under finger pressure for $30 \mathrm{~s}$, followed by a load of $5 \mathrm{Kg}(49 \mathrm{~N})$ for $5 \mathrm{~min}$ at room temperature $(18,19)$. After removal of excess provisional cement with a curette, the specimens were then thermal cycled in distilled water $(1,500$ cycles; $5^{\circ} \mathrm{C} / 55^{\circ} \mathrm{C}$, 40 seconds dwell time) and stored in distilled water at $100 \%$ relative humidity for $48 \mathrm{~h}$ at $37{ }^{\circ} \mathrm{C}$ prior to testing $(16,18,19)$.

The provisional crowns were then subjected to a tensile force in an Instron (Model 5966; Instron Corp, Norwood MA), operating at a cross-head speed of $1 \mathrm{~mm} / \mathrm{min}$, until dislodgement. The tensile strength values and mode of failure were recorded and an assessment was made of the integrity of the core build-up (Fig. 5B).

\section{Statistical Analysis}

The tensile force was selected as a primary variable in determining the power of the study. To compare two independent groups (buccal cusps only and all cusps removed) with repeated measures performed for the two proposed retention methods (pin-retention or non-pin retention). Considering a measure of variability of 0.59 the sample size provided a statistical power equal to $92 \%$ for the factor "group" and 96\% for the "group x retention" interaction, with a significance level of $5 \%$, and magnitude of effect (effect size) of 1.07 for the factor "group", and 1.20 for the "group $x$ retention" interaction.

Dichotomous and continuous data were submitted to a quantile normalization (Tukey's Ladder of Powers), since they did not fit model assumptions (data was shown slightly right-skewed). The outcome variables were compared by Three-way ANOVA Between Groups Designs, Balanced-N. The global effect of groups, retention method, build-up materials and their interaction were tested. Statistical significance was set at $p<0.05$ level. Analyses were performed using R Statistical Software Package with the Stats library 3.5.1 (R Foundation for Statistical Computing).

\section{Results}

Early Dislodgement or Failure of Build-Ups

Ninety-three of the ninety-six build-ups were retained
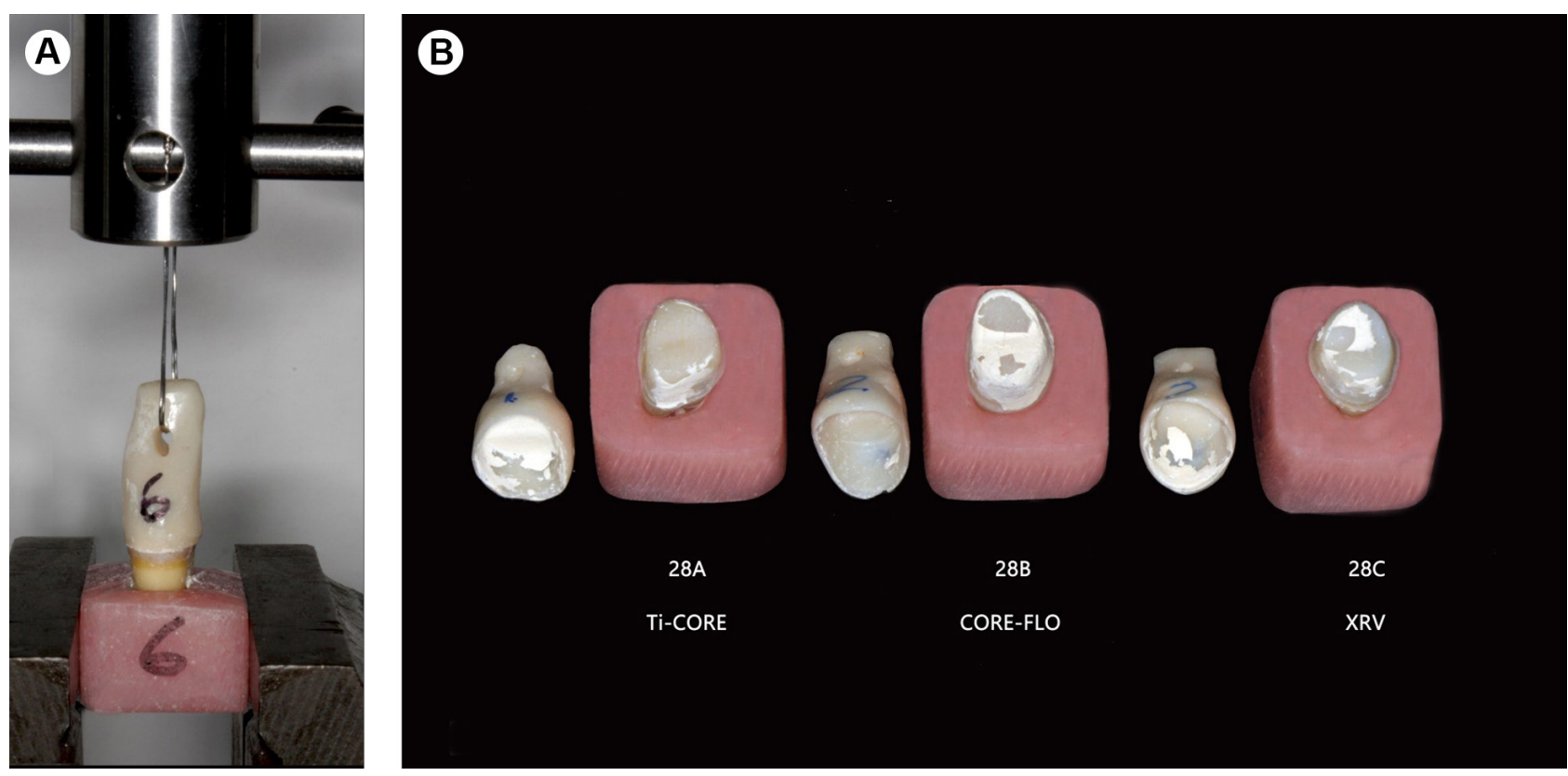

Figure 5. (A) Instron set up for tensile testing. (B) Representative specimens of Ti-Core Auto, Core Flo and Herculite XRV after provisional crown separation 
after the provisional crowns had separated from the tooth. The three build-ups that were catastrophic failures came from the non-pin retained group. Group 1 (buccal cusps removed) exhibited two failures with Core-Flo, and Group II (all cusps removed) exhibited one failure with Ti-Core. ANOVA with Tukey-transformed showed no significant main effects of group, retention and build-up materials, neither their interaction ( $p>0.05)$. Illustration of a line graph with error bars of the two-way interactions (Fig. 6) resulted from analysis of variance. In the left, irrespectively of build-up materials, it was observed that for both retention methods (pin and non-pin retained), the values of dislodgement/ failure are quite similar and seem to be slightly higher in the partial group (no significant differences were detected; $p>0.05$ ). Similar results were also observed when considering build-up materials and no group effect. The parallel group and build-up material profiles indicate absence of a statistical interaction between factors.

\section{Assessment of Force Required to Remove Temporary Crown}

A three-way analysis of variance was also conducted on the influence of the three independent variables (buccal cusps vs. all cusps removed; pin-retention vs. non-pin retention; Herculite XRV vs Core-Flo DC vs Ti-Core Auto E) on the maximum tension-force. The effect of tooth structure loss (buccal cusps only vs. all cusps) yielded an $F$ ratio of $1.294, p>0.05$, indicating that the effect of tooth structure missing was not significant. The effect of pin retention vs. retentive shoulder retention yielded an $F$ ratio of $3.181, p>0.05$, indicating the type of retention was not significant. Lastly, the effect of build-up material yielded and $F$ ratio of $0.468, p>0.05$, indicating that that type of material used was not significant. Taken together, the three-way interaction effect of tooth structure loss, retention type and build-up material was not significant yielding an $\mathrm{F}$ ratio of $0.026, p>0.05$. Representation of an interaction test of build-up materials and tooth structure loss (partial or whole cusps removal) at each retention level separately (Fig. 7). As the bar plots illustrates, the mean values of force were quite similar for both retention methods (pin and non-pin retained) and build-up materials; $p>0.05$. Tukey HSD posttests of pairwise comparisons on the main effects means was also performed (Fig. 8). No further significant differences were found ( $p>0.05$ ).

\section{Discussion}

Considering the results obtained in this in vitro study, both core build-ups with and without pins provided comparable retention and resistance to prevent early dislodgment of core build-ups during the fabrication of the final restoration. The amount of residual tooth structure without pins was a crucial factor. In other words, resistance of core build-ups without pins was directly related to the amount of remaining dentin, which corroborated the findings of other studies $(20,21)$. Decision-making process in placing composite core build-ups on severely broken-down vital teeth is a restorative challenge in daily practice. In order to provide a coronal core foundation for indirect restorations in cases of extensive loss of coronal structure, additional retentive features are required such as pins or auxiliary retentive preparation designs. Large core build-ups without pins frequently fail during final impression or upon removal of a provisional crown prior to cementing the definitive restoration (22-25). In this investigation, we assessed the effectiveness of a new restorative retentive method, "retentive shoulder design", to prevent early failure of resin core build-up materials without pins on compromised vital posterior teeth. Specifically, we evaluated the influence a retentive shoulder
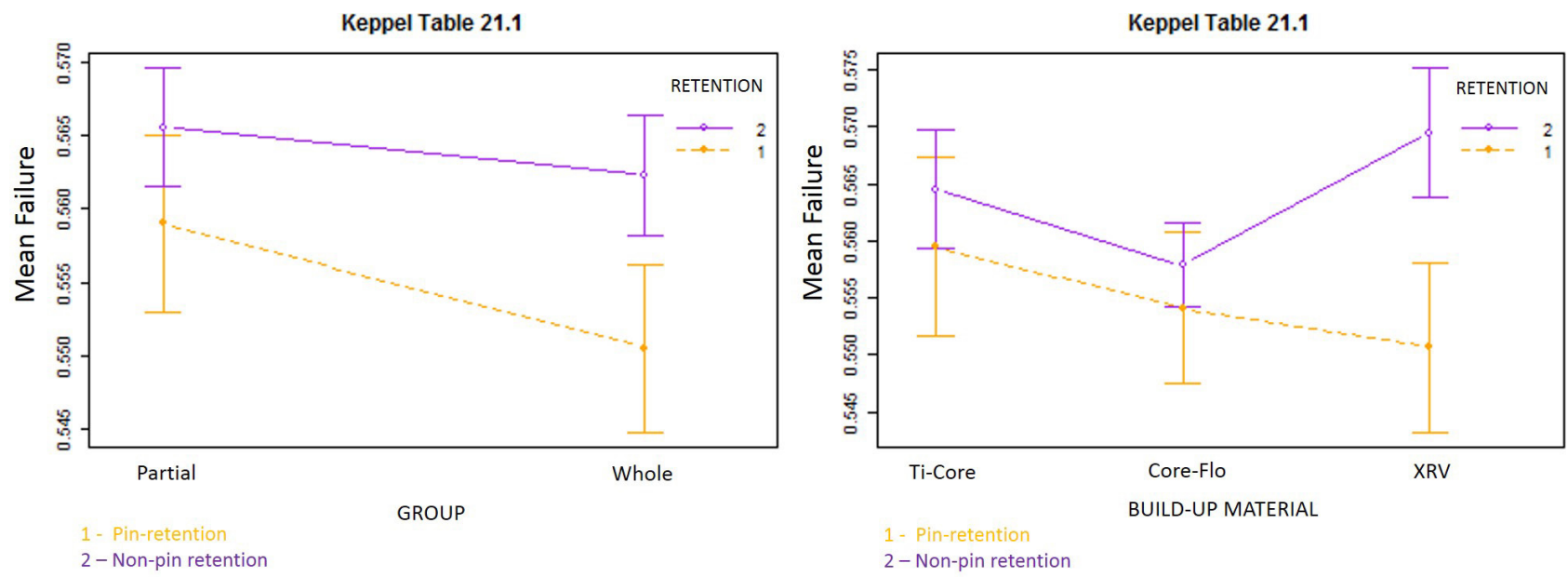

Figure 6. Line graph of means with error bars for the different levels of each factor after the two-way interactions 
design on three resin composite build-ups materials with difference physical and mechanical properties to withstand the tensile force required to remove provisional crowns.
The ability of these cores build-ups microhybrid, flowable, and titanium and lanthanide reinforced composite to resist dislodgment under tensile forces was very similar to the
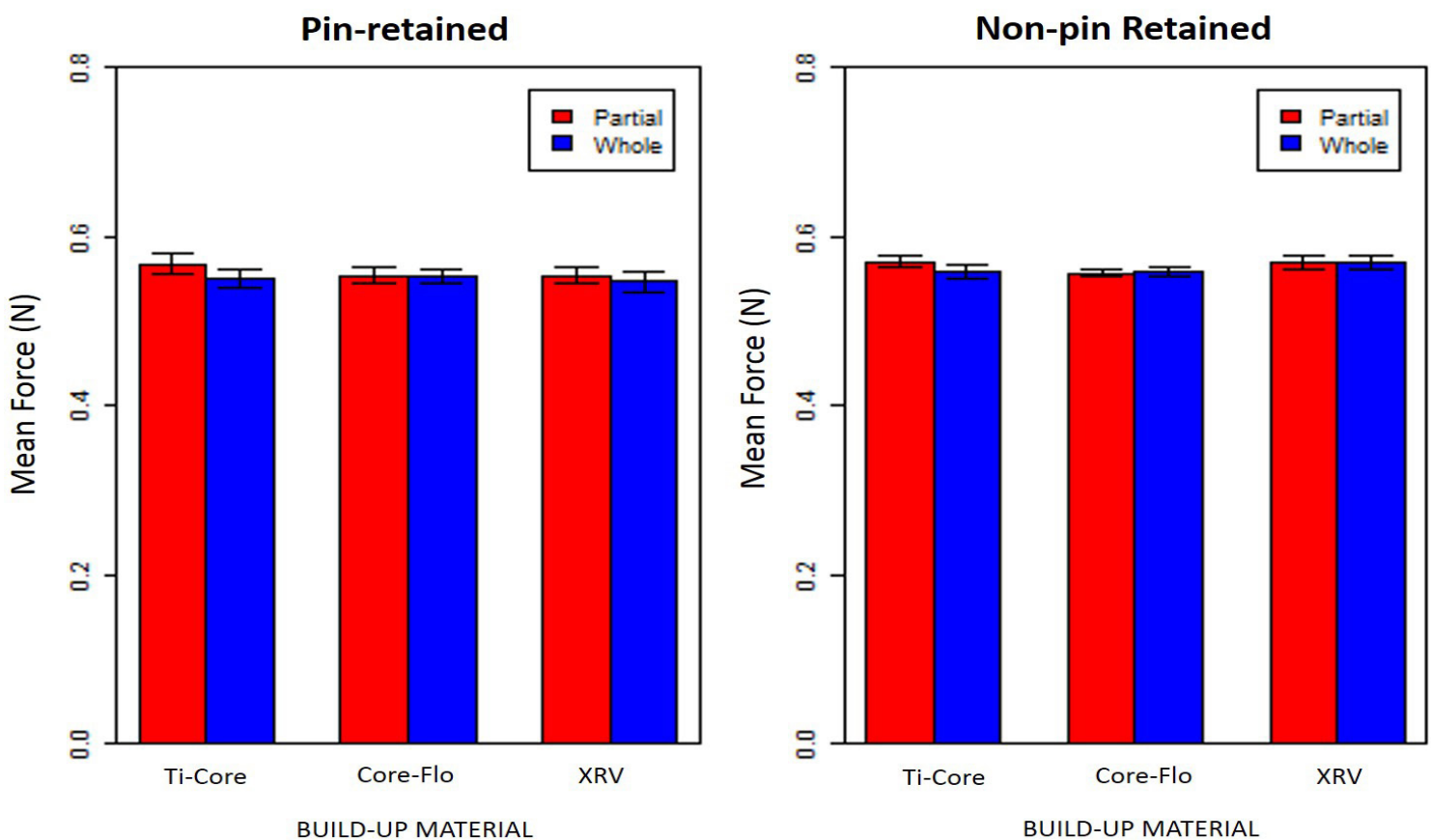

Figure 7. Bar graphs of core build-up materials interacted with partial or whole-cups removal. Retention methods are denoted by Pin-retained and Non-pin retained

$95 \%$ family-wise confidence leve

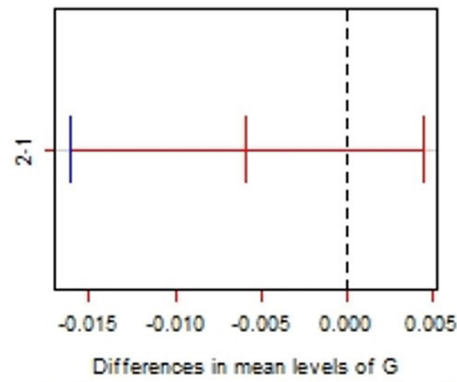

$95 \%$ family-wise confidence leve

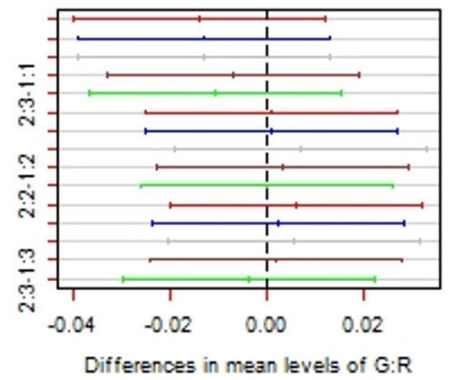

G= Groups

Blue: Partial (buccal cusps removed)

Red: Total (all cusps removed)

\section{$95 \%$ family-wise confidence level}

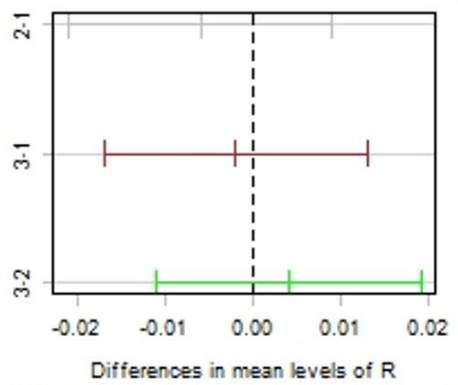

$95 \%$ family-wise confidence level

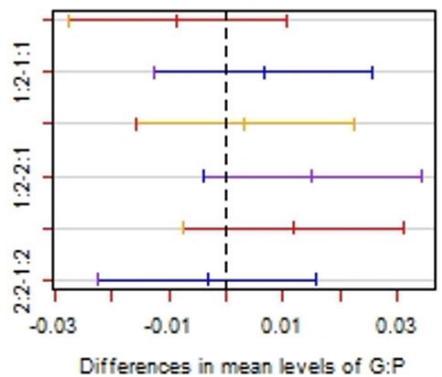

$\mathbf{P}=$ Preparation (Retention)

Yellow: Pin-retained

\section{$95 \%$ family-wise confidence level}

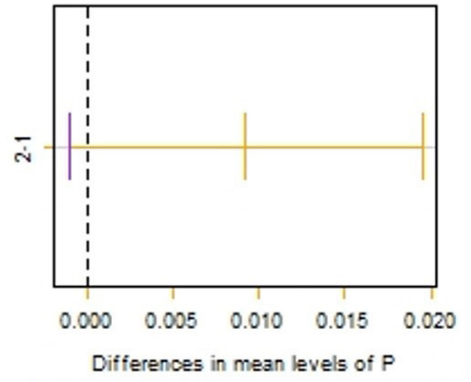

$95 \%$ family-wise confidence level

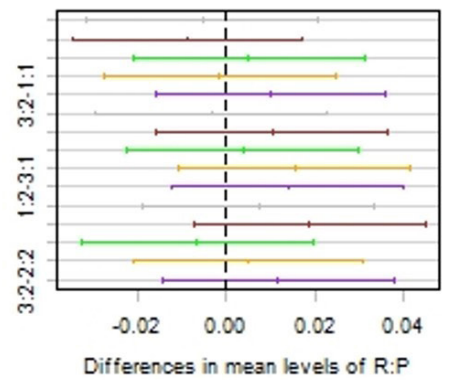

$\mathrm{R}=$ Resin (Build-ups)

Gray: Ti-Core

Brown: Ti-Core

Green: XRV

Figure 8. 95\% confidence intervals for $\mathrm{p}$ values after post tests of pairwise comparisons on the main effects means 
control groups, pin-retained core build-ups on partial or complete cusp coverage.

The null hypothesis that no differences would be observed between pin-retained and retentive shoulder design build-ups was confirmed, since statistical analysis did not demonstrate a significant interaction at the 5\% level between the whole-plot factors. Overall, both mean failure and mean tensile-force that was recorded until the provisional restoration separated were quite similar for the tested retentive methods. Regardless the extensive loss of structure, the method of retention, and without taking in consideration the composition of the restorative core material, the core build-ups resisted a mean tensile force of $50.62 \pm 14.94$ (Newtons, \pm SD) until the provisional crown was dislodged.

The reported values are similar to those published in the literature (22-24). Of the 96 teeth tested, only three buildups without pins failed along with the provisional crowns (3.12\%). This early dislodgement or failure of core build-ups was seen only in the first group of this study. Our results corroborate with failure rates that were reported in a few clinical studies of core build-ups, which ranged from $0 \%$ to $33 \%$ (21-26). Also, no significant differences were found comparing the different core build-up materials within the groups, which suggests that an effective bonding system and increased surface area seem to be more relevant than the composite resins that were used $(20,21)$.

Resin composites have a long history of being the preferred core build-up material with the main advantage of direct placement and immediate crown preparation. With high mechanical strength of resin cores, favorable bond strength to tooth structure, retentive shoulder design and at least $1 \mathrm{~mm}$ of natural tooth structure in the final preparation, resistance to tensile forces are established that can prevent early failures of core build-ups $(4,22-28)$. However, resin composites are technique sensitive and an incomplete monomer conversion during polymerization results in core build-ups that exhibit gap formation leading to microleakage and subsequent failure $(29,30)$. Furthermore, water sorption and a high coefficient of thermal expansion are additional shortcomings that affect the results (31-33).

The results of this study have shown that a retentive shoulder design can be used as an alternative to pin retention. Further studies will be needed to evaluate the retentive shoulder preparation in relation to volumetric dimensional changes of resin core build-ups in an aqueous environment and with prolonged thermal cycling as 1500 cycles in the present study may not be indicative of the long-term effects on the core build-ups. Other studies suggested that 6,000 cycles will be required to simulate approximately 5 years of service in the oral cavity $(20,34)$. It should also be pointed out that the teeth in this experiment were not subjected to functional loading cycles simulating mastication and associated stresses which typically would be the case in the oral environment $(22,35)$.

It was observed that the mode of failure when examined at $\mathrm{x} 40$ with a stereomicroscope indicated an adhesive failure. There was no evidence of fracture of the retentive shoulder, therefore adhesive failures were a function of the bonding agent as opposed to the shoulder design. Close examination of tooth structure following the loss of a core build-up revealed no damage to the shoulder. Clinical studies are recommended to confirm the findings that are reported here. It appears that the retentive shoulder may offer a viable alternative for core build-up retention to prevent early failures. The retentive shoulder design offers a faster, more conservative and safer approach that negates the risks of pin placement, and can readily be incorporated in clinical practice.

The use of pins will probably continue to decrease given the risks of placement and the advent of more durable adhesive bonding agents and composite resins $(6,35,36)$. This in vitro research proved and concluded that the retentive shoulder design offers a conservative and safe approach in the prevention of early failures by enhancing and increasing the micro retention and resistance form of core builds-ups when restoring structurally compromised vital posterior teeth. By achieving a strong and lasting core foundation, we can ultimately help assure the long-term success of the final indirect restoration.

Under the conditions of the present research, it can be concluded that pin-retained and a retentive shoulder design presented no significant differences with respect to retention of a core build-up material that supports provisional crowns. Both methods showed similar values of failure under tensile-force in the removal of provisional crowns. There was no significant interaction between the relative effects of occlusal reduction (partial or whole cusps), retention (pin-retained or retentive shoulder design), and core build-up materials. With the advent of adhesive bonding systems, the retentive shoulder design and increased tooth structure surface can contribute to stabilize the core foundation to prevent early failures of core build-ups during restorative procedures of indirect restorations.

\section{Resumo}

Este estudo avaliou a influência de um preparo retentivo em forma de ombro para prevenir a falha precoce de núcleos de preenchimento realizados em molares com 3 diferentes tipos de resina composta. Noventa e seis terceiros molares superiores hígidos extraidos de humanos, foram divididos em dois grupos $(n=48)$ de acordo com o tipo de redução oclusal: em todas as cúspides (total) ou nas cúspides vestibulares (parcial). Os grupos foram divididos em dois subgrupos: núcleos retidos a pinos 
e não retidos a pinos, resultando em quatro grupos $(n=24)$ : redução oclusal total/retido a pino, redução oclusal parcial/retido a pino, redução oclusal total/não retido a pino, redução oclusal parcial/não retido a pino. A redução oclusal foi de $3 \mathrm{~mm}$ com um ombro retentivo semilunar de $3 \mathrm{~mm}$ e uma altura de parede axial de 1,5 $\mathrm{mm}$. Os grupos foram restaurados utilizando resina composta microhibrida, fluivel ou reforçada com titânio. Foram confeccionadas coroas provisórias de resina acrilica autopolimerizável modificada, cimentadas com cimento provisório sem eugenol e termocicladas. Uma máquina universal de ensaios foi utilizada para tracionar as coroas provisórias paralelamente ao longo eixo do dente até o seu deslocamento. Análise de variância de 3 fatores foi aplicada para avaliar o efeito dos fatores na retenção do núcleo. Noventa e três núcleos de preenchimento permaneceram retidos sob a carga de tração, enquanto três núcleos de preenchimento sem pinos foram deslocados. A análise de variância não mostrou diferença significante entre os núcleos de preenchimento com desenho retentivo e os núcleos de preenchimento retidos a pinos. Com o advento dos sistemas adesivos, o aumento da área de superficie e o desenho retentivo dos ombros podem fornecer um preparo retentivo para evitar falhas precoces nos núcleos de preenchimento durante a fabricação de restaurações indiretas, o que contribuirá para a longevidade das restaurações finais.

\section{Acknowledgements}

This research did not receive any specific grant from funding agencies in the public, commercial, or not-for-profit sectors. This research was presented at CDA table clinic on preliminary results by dental student, Charlotte Ettesse and it was awarded the second place on May 5, 2017 at CDA Anaheim Convention Center.

\section{References}

1. Reddy SN, Harika K, Manjula S, Chandra P, Vengi L, Koka KM. Evaluation of occlusal fracture resistance of three different core materials using the Nayyar core technique. J Int Soc Prev Community Dent 2016;6:4043

2. Lilaj B, Franz A, DangI V, Dauti R, Moritz A, Cvikl B. Shear bond strength of different materials used as core build-up to ceramic. Am J Dent 2017;30:243-247.

3. Gowda S, Quadras DD, Sesappa SR, Kumar L, Kulkarni D, Mishra N. Comparative evaluation of fracture strength of different types of composite core build-up materials: an in vitro study. J Contemp Dent Pract 2018;19:507-514

4. Combe E, Shaglouf A, Watts D, Wilson N. Mechanical properties of direct core build-up materials. Dent Mater 1999;15:158-165.

5. Kumar G, Shivrayan A. Comparative study of mechanical properties of direct core build-up materials. Contemp Clin Dent 2015;6:16-20

6. Christensen G. Building up tooth preparations for full crowns-2000. J Am Dent Assoc 2000;131:505-506.

7. Felton D, Webb E, Kanoy B, Cox C. Pulpal response to threaded pin and retentive slot techniques: a pilot investigation. J Prosthet Dent 1991;66:597-602.

8. Mamoun J. Post and core build-ups in crown and bridge abutments: Bio-mechanical advantages and disadvantages. J Adv Prosthodont 2017;9:232-237.

9. Lo CS, Millstein PL, Nathanson D. In vitro shear strength of bonded amalgam cores with and without pins. J Prosthet Dent 1995;74:385-391.

10. Ersoz E: Evaluation of stresses caused by dentin pin with finite elements stress analysis method. J Oral Rehabil 2000;27:769-773.

11. Yu C, Abbott PV. An overview of the dental pulp: its functions and responses to injury. Aust Dent J 2007;52:S4-S16.

12. Wassell RW, Smart ER, St George G. Crowns and other extra-coronal restorations: cores for teeth with vital pulps. Br Dent J 2002;192:499-502.

13. Mamoun JS, Cervini EJ. A pin amalgam or composite core foundation technique for teeth with minimal coronal structure. J Prosthet Dent 2004;91:599-602

14. Vaught R. Mechanical versus chemical retention for restoring complex restorations: what is the evidence? J Dent Educ 2007;71:1356-1362.

15. Bonilla ED, Del Aguila CL, Bonilla SC. Eating Disorders: Diagnosis and
Prosthodontic Management. BAOJ Dentistry 2017:3:1-12.

16. Bonilla ED, Mardirossian G, Caputo AA. Fracture toughness of various core build-up materials J Prosthod 2000;9:14-18.

17. Caputo AA, Standlee JP: Pins and post-why, when, and how. Dent Clin North Am 1976;20:299-311

18. Wiskott HWA, Nichols JI, Belser UC. The effect of tooth preparation height and diameter on the resistance of complete crowns to fatigue loading. Int J Prosthodont 1997; 10:207-215

19. Piemjai M. Effect of seating force, margin design and cement on marginal seal and retention of complete metal crowns. Int J Prosthodont 2001;14:412-416

20. Pantaleon DS, Morrow BR, Cagna DR, Pameijer CH, Garcia-Godoy F. Influence of remaining coronal tooth structure on fracture resistance and failure mode of restored endodontically treated maxillary incisors. $J$ Prosthet Dent $2018 ; 27: 13-19$

21. Zhang YY, Peng MD, Wang YN, Li $Q$. The effects of ferrule configuration on the anti-fracture ability of fiber post-restored teeth. J Dent 2015;43:117125.

22. Lewinstein I, Chweidan H, Matalon S, Pilo R. Retention and marginal leakage of provisional crowns cemented with provisional cements enriched with chlorhexidine diacetate. J Prosthet Dent 2007;98:373-378

23. Burke FJ, Shaglouf AG, Combe EC. Fracture resistance of five pinretained core build-up materials on teeth with or without extra coronal preparations. Oper Dent 2000;25:388-394.

24. Mamoun JS, Cervini E. A pin amalgam or composite core foundation technique for teeth with minimal coronal structure. The Journal of Prosthetic Dentistry 2004;91:599-602.

25. Bonilla ED, Mardirossian G, Caputo AA. Fracture Toughness of posterior resin composite. Quintessence Int 2001;32:206-210.

26. Tachibana K, Kuroe T, Tanino Y, Satoh N, Ohata N, Sano H, Caputo AA. Effects of incremental curing on contraction stresses associated with various resin composite buildups. Quintessence Int 2004;35:299-306.

27. Cohen BI, Pagnillo MK, Newman I, Musikant BL, Deutsh AS. Retention of a core material supported by three post head designs. J Prosthet Dent 2000;83:624-628.

28. Manhart J, Kunzelmann KH, Chen HY, Hickel R. Mechanical properties and wear behavior of light-cured packable composite resins. Dent Mater 2000;16:33-40

29. Tarle Z, Meniga A, Knezevic A, Sutalo J, Ristic M, Pichler G. Composite conversion and temperature rise using a conventional, plasma arc, and an experimental blue LED curing unit. J Oral Rehabil 2002;29:662-667.

30. Passos SP, Freitas AP, Jumaily S, Santos MJ, Rizkalla AS, Santos GC Jr. Comparison of mechanical properties of five commercial dental core build-up materials. Compend Contin Educ Dent 2013;34:62-63,65-68

31. Bastioli $C$, Romano G, Migliaresi C. Water sorption and mechanical properties of dental composites. Biomaterials 1990;11:219-223

32. Chutinan S, Platt JA, Cochran M, Cochran MA, Moore BK. Volumetric dimentional change of six direct core materials. Dent Mater 2004;20:345351

33. Alshali RZ, Salim NA, Satterthwaite JD, Silikas N. Long-Term sorption and solubility of bulk-fill and conventional resin composites in water and artificial saliva. J Dent 2015;43:1511-1518

34. Naumann M, Preuss A, Rosentritt M. Effect of incomplete crowns ferrules on load capacity of endodontically treated maxillary incisors restored with fiber posts, composite build-ups, and ceramic crowns: an in vitro evaluation after chewing simulation. Acta Odontol Scand 2006;64:31-36.

35. Stober $T$, Rammelsberg P. The failure rate of adhesively retained composite core build-ups in comparison with metal-added glass ionomer core build-ups. J Dent 2005;33:27-32

36. Bitter K, Schubert A, Neumann K, Blunck U, Sterzenbach G, Rüttermann $\mathrm{S}$. Are self-adhesive resin cements suitable as core build-up materials? Analysis of maximum load capability, margin integrity, and physical properties. Clin Oral Investig 2016;20:1337-1445.

Received April 11, 2019 Accepted July 5, 2019 